\title{
Is Library Database Searching a Language Learning Activity?
}

\section{Karen Bordonaro}

This study explores how non-native speakers of English think of words to enter into library databases when they begin the process of searching for information in English. At issue is whether or not language learning takes place when these students use library databases. Language learning in this study refers to the use of strategies employed by students to develop English vocabulary knowledge. This study found that international students do seem to engage in language learning when using library databases, and it identifies and describes their strategies.

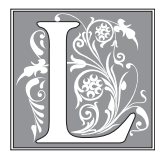

ibrary database searching is a key activity that takes place in and through university libraries in North America on a daily basis. As a core activity, searching for information through library databases offers students an important way to access and retrieve relevant material for their academic needs. Library database searching has been the topic of investigation in the library literature mainly through the lens of information-seeking behavior. How people find information is of great interest to the profession both on a theoretical and on a practical level, because a better understanding of their information-seeking behavior may lead to better meeting their information needs.

This study looks at the activity of library database searching through a different lens, that of language learning. Language learning as used in this article refers to the use of strategies employed by non-native speakers of English to improve and expand their knowledge of English vocabulary. The key research question of this study is: Is library database searching a language learning activity in addition to being a means for finding information? Why this question may be important is that international students who are nonnative speakers of English comprise a large and growing minority of university students in North America. In the current academic era in which internationalization efforts at universities in both the United States and Canada are intensifying, it might behoove us to better understand how international students use our libraries. An investigation of language learning in this context may underscore our own importance in terms of both supporting students' information needs and in helping them to develop their English language proficiencies to better navigate the academic world.

\section{Literature Review}

International students who are non-native speakers of English in North America

Karen Bordonaro is Instruction Coordinator/Liaison Librarian for Applied Linguistics and Modern Languages in the James A. Gibson Library at Brock University; e-mail: kbordonaro@brocku.ca. (C) Karen Bordonaro 
are a topic of investigation in the library literature. ${ }^{1}$ A comprehensive annotated bibliography on international students in U.S. libraries compiled by Kaetrena D. Davis provides a chronological overview of how this student group has been studied from the 1970s to the present day. She notes that works produced in the 1980s addressed questions of cultural differences and library literacy levels, the 1990s produced more diversified studies investigating technology, information literacy, and information seeking, and 2000-2005 gave us research studies about international students that looked at information literacy and instruction issues in an even more global context. ${ }^{2}$

Within these broader areas of investigation (information literacy, cultural issues, technology), several studies have focused on language learning issues in relation to library use by non-native speakers of English. Macdonald and Sarkodie-Mensah, for example, note that code-switching is a language phenomenon put into practice by librarians unused to communicating with students whose primary language is other than English:

The situations... require what linguists term code-switching, the adjustment of language to accommodate the needs of a listener. We all code-switch naturally when we address children, for example; we consciously or unconsciously code-switch when we perceive our listeners to have little education, or little understanding of a technical subject...The problem is that people unaccustomed to addressing nonEnglish speakers often fall back on their previous code-switching experience, with results that can be patronizing or worse, for college-level ESL [English as a second language] students are neither childlike nor poorly educated. ${ }^{3}$

The need for native English speaking academic librarians to become aware of the linguistic and cultural differences between themselves and international students remains a constant, if small, thread in the library literature. Several articles appearing in the library literature seem to meet this need by describing general language learning theories in a way that would make sense to librarians. Conteh-Morgan, for example, notes that understanding how language is learned is crucial to successful instruction efforts with international students: "Awareness of theories of second language learning and approaches to teaching is vital if librarians are to provide more meaningful instruction to LEP [Limited English Proficiency] students." ${ }^{4}$ Wang, in another example, provides a helpful overview of sociocultural learning theories and collaborative learning models to tie them to information literacy efforts. ${ }^{5}$ And Amsberry describes the concept of "teacher talk" as a potential barrier to classroom communication with international students. ${ }^{6}$

Moving from theory to practice, further studies in the library literature offer practical suggestions as to how to take this knowledge of language learning and put it to good use when working with international students. Some of these ways include: offering library instruction sessions for international students that incorporate language acquisition concerns along with the development of library skills, ${ }^{7}$ enabling librarians to work on a more meaningful level with this group of students, ${ }^{8}$ learning more about international students' initial level of library knowledge before designing programs, ${ }^{9}$ and considering language needs of international students in one-onone transactions as well as in classroom settings. ${ }^{10}$

Directly connecting language learning to library use from the perspective of international students is another compelling way to investigate these issues. DiMartino, Ferns, and Swacker, for instance, investigated what CD-ROM searching techniques ESL students use and discovered that: "The main difficul- 
ties of ESL students that differed significantly from those of native speakers of English were concentrated in vocabulary issues-utilization of plural forms, and the use of synonyms and expanded concepts for more robust searching."11 In a similar way, Zhuo, Emanuel, and Shuqin explored how international students used specialized language features in library resources such as foreign language interfaces and used their results to call for bilingual library instruction and multilingual library tutorials. ${ }^{12}$ My own initial work on how non-native speakers of English use university libraries for self-directed language learning purposes also falls into this category of investigating library use from the perspective of international students. ${ }^{13}$

The purpose of this current study is to update and enhance earlier work done on how specific language use is engaged in by non-native speakers of English in university libraries. Its intent is to examine language use in library database searching by looking at what vocabulary strategies are employed by graduate students when searching for information.

\section{Methodology}

This study used a qualitative research design. As such, I collected the words of the participants themselves to serve as the data from which findings could arise. I specifically targeted as potential participants the graduate students in two academic disciplines, those of Education and Applied Linguistics. I felt that these two groups of graduate students would offer a potentially rich source of data about language use because they are involved in the study of language and learning issues themselves. I also thought they might have a strong ability to articulate their reasons for engaging in various vocabulary strategies at a high level of linguistic competence.

I therefore sent a direct solicitation for potential participants through an email invitation to two target programs: an International Student Program (ISP) stream of an M.Ed. degree program and a Bridging Program for international students in an M.A. Teaching English as a Subsequent Language (TESL) degree program. All fifteen students in the ISP M.Ed. program participated, as did all seven students in the M.A. TESL Bridging Program. Twenty of the participants were native Chinese speakers, one was a native Korean speaker, and one was a native Arabic speaker. All of the students are graduate students at a midsized Canadian university in southern Ontario.

It should also be noted that I knew most of the participants through my role as liaison librarian for the departments of both Applied Linguistics and Education at the time this study was conducted. The participants therefore recognized me as a librarian and also as someone interested in language issues. While this may be construed as a strength during the interviewing process because the participants felt comfortable speaking to me, it could also have led them to answer questions in a certain way so as to please me. To prevent this, I stressed the lack of "right answers" or "wrong answers" by making a concerted effort to assure them that there was no single right way or wrong way to search. The participants were told explicitly that this was a library research study. So although they were aware that I was asking about language issues, I kept the focus on the main question: How do you decide what words to type into a database when you first begin looking for library information?

The data collection consisted of a series of interviews. Every participant was interviewed through a semistructured interview format for approximately 45-60 minutes, with follow-up questions and answers conducted by e-mail. The semistructured interview questions asked one general, open-ended question followed by a series of more structured questions. The open-ended question was:

How do you decide what words in English to enter into a database or search engine when you are looking for journal articles? 
I used the phrase "search engine" when posing this question because my experience in working with international students one-on-one told me that this is a common way for them to refer to library searching. I also added the phrase "journal articles" because that is the type of information commonly sought by Education and Applied Linguistics when using library databases. It should be noted, however, that my initial use of the phrase "journal articles" did not dismiss any subsequent discussion of book searching either. It was simply meant as a more concrete starting point than just inquiring about online searching in general that may have resulted in all Google-based answers. After soliciting their input from this main question, I then asked them more specific questions to probe deeper answers in terms of how and why they did their searching. These more specific questions covered the topics of finding more vocabulary, keeping track of vocabulary use, and using library strategies:

\section{Finding More Vocabulary}

- Do you rely on your own knowledge of English vocabulary?

- How would you rate your own knowledge of English vocabulary? (excellent - good-fair-poor)

- Do you use a dictionary?

- Do you use a thesaurus?

- Do you ask your classmates for help?

- Do you ask your professor for help?

- Do you use your textbook to find appropriate vocabulary words?

- Do you use other readings to find appropriate vocabulary words?

- When a search is not successful, how do you think of other words to try?

- How do you increase your own vocabulary of English in general?

\section{Keeping Track of Vocabulary}

- Do you keep track of what vocabulary you have used for searches?

- Do you write down the words or memorize them?
- Do you print out search results so you know what words you used to find them?

- Do you use any other vocabulary strategies?

\section{Library Strategies}

- Do you use the ERIC thesaurus to find better subject headings?

- Do you look at the other subject headings in a record?

- Do you use library database options like "find related articles"?

- Do you ask librarians or library assistants for help?

- Do you use any other library strategies to find better words to search on?

All of the participants were asked all nineteen of the bulleted questions above. All participant interviews were recorded orally through the use of the open-source software known as Audacity. No audiovisual files were produced as I wanted to concentrate on the actual words spoken by participants as the basis for results. The audio files were recorded live for each interview and then transcribed afterwards individually by me. Complete transcriptions were produced for each audio file. Each transcription was then coded for types of strategies that appeared, both vocabulary learning strategies and library searching strategies. The coding took place in two stages. In the first stage, I identified words and phrases in the transcripts initially as "vocabulary strategy" or "library strategy." In the second stage, I sought to categorize what type of specific strategy was represented ("guessing words in context," "citation chasing"). The second level of coding made use of some phrasing that appeared on the question sheet, but other category codes came from my own knowledge of applied linguistics, education, and librarianship. In all cases, the words of the participants themselves served as the baseline data, and I simply put category labels on those words to group the responses by type. 


\section{Findings}

Sources of initial vocabulary knowledge in terms of what words to type in at the start of a search included the following sources: self-knowledge, the instructor (approaching an instructor both individually after a lecture and by listening to an instructor during a lecture) and course material (from the textbook and from course readings). The participants rated their own self-knowledge of the subject area quite highly although they then rated their own knowledge of English vocabulary in general as "fair" but not "excellent." This may mean that, as graduate students, they consider their content knowledge of specialized termi- nology in the fields of Education and Applied Linguistics to be advanced. So when they first begin a search, they begin with words they have seen and used in their classes. They do not begin with a list of synonyms or other backup terms to use if their initial search fails.

If a search does fail to produce the desired results, then all the participants do use a number of strategies to come up with new words or phrases to try. The participants employ both vocabulary strategies and library strategies to try to think of additional words to search on. Tables giving examples of the strategies appear below. The strategies in the tables are arranged in the chronological order in which they

\begin{tabular}{|c|c|c|}
\hline \multicolumn{3}{|c|}{$\begin{array}{c}\text { TABLE } 1 \\
\text { Vocabulary Strategies }\end{array}$} \\
\hline Student Quotes & Vocabulary Strategy & $\begin{array}{l}\text { Occurrences } \\
\text { per Strategy }\end{array}$ \\
\hline I check the online dictionary. & Using a dictionary & 20 \\
\hline I use Microsoft word thesaurus. & Using a thesaurus & 6 \\
\hline $\begin{array}{l}\text { I guess through the relationship between } \\
\text { some of the words. }\end{array}$ & Guessing words in context & 15 \\
\hline $\begin{array}{l}\text { If I could see the word over and over } \\
\text { again, then I could remember it. }\end{array}$ & $\begin{array}{l}\text { Salience and frequency } \\
\text { (noticing) }\end{array}$ & 17 \\
\hline I sometimes try to memorize new words. & Memorization & 10 \\
\hline I say them days and days. & Repetition & 8 \\
\hline $\begin{array}{l}\text { I keep a pen and underline the words } \\
\text { which I don't understand. }\end{array}$ & $\begin{array}{l}\text { Marking unknown words } \\
\text { (underlining, circling) }\end{array}$ & 14 \\
\hline $\begin{array}{l}\text { I collect a lot of words. I have a word list } \\
\text { file. }\end{array}$ & Writing lists & 6 \\
\hline $\begin{array}{l}\text { I remember if this word occurs frequently } \\
\text { in the lecture. }\end{array}$ & Listening to lectures & 12 \\
\hline Sometimes I ask my classmates. & Asking classmates, instructor & 13 \\
\hline $\begin{array}{l}\text { I keep reviewing it, one day, two days, one } \\
\text { week, maybe a month later. }\end{array}$ & Reviewing word lists & 4 \\
\hline $\begin{array}{l}\text { I cannot just look at it and learn it. I have } \\
\text { to visualize the word, maybe it's because } \\
\text { of my L1 [Chinese]. }\end{array}$ & Visualization & 4 \\
\hline [I use] the reading material from class. & $\begin{array}{l}\text { Going back to textbook, } \\
\text { readings }\end{array}$ & 18 \\
\hline Sometimes I change the part of speech. & $\begin{array}{l}\text { Trying different parts of } \\
\text { speech }\end{array}$ & 2 \\
\hline
\end{tabular}




\begin{tabular}{|c|c|c|}
\hline \multicolumn{3}{|c|}{$\begin{array}{c}\text { TABLE } 2 \\
\text { Library Strategies }\end{array}$} \\
\hline Student Quotes & Library Strategy & $\begin{array}{l}\text { Occurrences } \\
\text { per Strategy }\end{array}$ \\
\hline $\begin{array}{l}\text { I try to look at the references that the } \\
\text { article uses. }\end{array}$ & Using references & 12 \\
\hline $\begin{array}{l}\text { Maybe sometimes you find one refer- } \\
\text { ence, then you can find some more } \\
\text { information about this concept. }\end{array}$ & Citation chasing & 14 \\
\hline I will ask someone to help me, like you. & Asking librarian for assistance & 10 \\
\hline $\begin{array}{l}\text { I type in social linguistic and then a } \\
\text { star or question mark. }\end{array}$ & Truncation/wildcard searching & 3 \\
\hline First we want to find a famous author. & $\begin{array}{l}\text { Searching for known authors, } \\
\text { researchers }\end{array}$ & 15 \\
\hline $\begin{array}{l}\text { Ifocus in on one journal like Teacher } \\
\text { Leadership. }\end{array}$ & Field searching & 7 \\
\hline $\begin{array}{l}\text { Last time I did a paper and wanted } \\
\text { something on educational philosophy. } \\
\text { But when I look...there were no books. } \\
\text { So I just try philosophy and then I got } \\
\text { two books. }\end{array}$ & Broadening a search & 5 \\
\hline $\begin{array}{l}\text { I narrow it ... if I know a particular } \\
\text { year of publication, author name or } \\
\text { topic for search. }\end{array}$ & Narrowing a search & 8 \\
\hline $\begin{array}{l}\text { I use OED...sometimes I use it to really } \\
\text { learn about a word. }\end{array}$ & Using etymology dictionary & 1 \\
\hline I will go to the ERIC thesaurus. & Using ERIC Thesaurus & 10 \\
\hline $\begin{array}{l}\text { I just use what I know for the descrip- } \\
\text { tors. }\end{array}$ & Using descriptors & 7 \\
\hline $\begin{array}{l}\text { I do the journal search. Maybe in that } \\
\text { journal there are some other articles } \\
\text { related. }\end{array}$ & $\begin{array}{l}\text { Searching for known journal } \\
\text { titles }\end{array}$ & 5 \\
\hline I look at the summary. & Reading abstracts & 8 \\
\hline $\begin{array}{l}\text { Because the order is most relevant, then } \\
\text { relevant, then not quite relevant, but } \\
\text { still has some connection, from the top } \\
\text { to the bottom. }\end{array}$ & Using relevance rankings & \\
\hline Because it is a computer, not a brain. & Word appearance $\neq$ semantics & 1 \\
\hline I look at the date too. & Considering currency (dates) & 4 \\
\hline $\begin{array}{l}\text { The professor mentioned in the class } \\
\text { one day when you are searching for } \\
\text { articles, use descriptors. }\end{array}$ & $\begin{array}{l}\text { Library strategies from instruc- } \\
\text { tors }\end{array}$ & 6 \\
\hline $\begin{array}{l}\text {... know where these kinds of books } \\
\text { are, and then I can go there to find } \\
\text { some more information. }\end{array}$ & Browsing shelves & 2 \\
\hline
\end{tabular}


appeared during the course of the interviews. In addition to listing the strategies and offering examples from the data, each table also includes the number of times the participants invoked this particular strategy. Table 1 lists vocabulary strategies and table 2 lists library strategies.

Vocabulary strategies verbalized by the participants include using a dictionary or thesaurus, guessing words in context, noticing strategies of salience and frequency, memorization, repetition, marking unknown words, writing lists, listening to lectures, asking classmates, reviewing word lists, visualization, going back to the textbook, readings, and lecture notes, and trying different parts of speech.

Library strategies include using references, citation chasing, looking at tables of contents, asking a librarian for help, truncation and wild card searches, searching for known authors and researchers, field searching, broadening and narrowing searches, using an etymology dictionary, using the ERIC thesaurus, using descriptors, searching for known journal titles, reading abstracts, using relevance, knowing that the appearance of a word in a database does not necessarily equal a semantic match, considering currency, employing library strategies offered by instructors, and browsing shelves.

All of the strategies that the participants identified appear in these categories in tables 1 and 2 . There were no strategies verbalized that did not fit any category listed. Some of the categories listed directly reflect the content of some of the questions that were asked. In terms of vocabulary strategies that appeared on the question sheet, participants confirmed using a dictionary, using a thesaurus, asking classmates or the professor for help, and using the textbook and other readings. In terms of library strategies present on the question sheet, participants stated their use of the ERIC thesaurus, other subject headings, and asking a librarian for assistance.

Other categories listed in tables 1 and 2 came not from the guided question sheet but directly from the voices of the participants themselves. Vocabulary strategies that appeared spontaneously in the interviews were: guessing words in context, saliency and frequency (noticing), memorization, repetition, marking unknown words, writing lists, listening to lectures, reviewing word lists, visualization, and trying different parts of speech. The library strategies that arose directly from the participants themselves included truncation/wildcard searching, broadening and narrowing searches, using an etymology dictionary, searching for known journal titles, reading abstracts, using relevance rankings, understanding word semantics in searching, considering currency, getting library strategies from instructors, and browsing shelves.

\section{Vocabulary Strategies as Language Learning}

A number of vocabulary strategies were identified and described by the participants during the interviews. The most frequently occurring vocabulary strategies in this study are those used often in language classrooms (using a dictionary, salience, guessing words in context) and in classrooms in general (referring to textbooks and asking classmates).

All of the participants viewed the use of vocabulary strategies in general as a form of language learning whether or not they were consciously doing this in a library setting. Perhaps this is because many vocabulary learning strategies are explicitly taught in language classes. ${ }^{14}$ For instance, every non-native speaker of English who has taken a class in reading is generally taught intensive reading strategies such as GWIC (guessing words in context). This reading strategy refers to making an educated guess about the meaning of an unknown word by examining the words surrounding it. The explicit teaching of a reading strategy like GWIC is thought to produce faster readers who do not need to look up every unknown word in a dictionary as they work their way through sometimes lengthy texts in English. 
The other types of vocabulary strategies that surfaced in this study are also well-known language learning strategies. Salience and frequency, for example, are linguistic devices that consciously ask a student to notice words that appear over and over again in a text from which their importance can then be determined. This reading strategy acclimatizes students to finding and understanding the most important content words in a text. Creating word lists and memorizing words are also familiar methods for non-native speakers to learn native vocabulary. Trying different parts of speech (changing an adjective to a noun, for example) is another common grammatical way to learn more word forms. Using a dictionary to find meanings and a thesaurus to find synonyms are also widely practiced when acquiring a new language.

So it is not surprising that the use of these strategies to find new words to search on would appear to be language learning strategies to non-native speakers of English using an authentic language tool like a library database. The participants may have internalized these learning techniques so well from language classrooms that they are able to apply them equally well to an authentic language environment such as the library. And, in fact, the participants' use of such vocabulary strategies strengthens the position of the library as a place where engaging in authentic, real-life use of English is not only possible, but encouraged, to obtain best results.

\section{Library Strategies as Language Learning}

A number of library strategies were also identified and described by participants during the course of these interviews. In terms of frequently occurring library strategies, the most commonly mentioned strategies seem to come from known item searching and from the assistance of a librarian. Searching for familiar authors and citation chasing are two examples of beginning a library search with known information. A search conducted in this manner starts with either the bibliography of an article or self-knowledge of well-known researchers in a field. This type of searching is often associated with faculty members. Its appearance in this study may indicate that these graduate students are becoming immersed in their disciplines as fledging researchers. The other frequently occurring library strategies, asking a librarian for assistance and using the ERIC thesaurus, may have come from library workshops attended by the participants. Through these workshops, the participants had been exposed to these sources of assistance early on in their academic studies.

When the participants initially described their use of these strategies listed above (citation chasing, using descriptors, and so on), they viewed these actions as library searching only. When asked more deeply to describe just how and why they engaged in these actions, every participant then noted that language learning was involved. The main difference in answers between participants at this point hinges on whether or not they thought that they were consciously or unconsciously learning new vocabulary words through their library database searching activities.

The vast number of participants, eighteen out of twenty-two, thought that their learning of new vocabulary through the use of library strategies was an unconscious way to improve their English vocabulary. They stated that their main goal in using library databases was to find information. One participant put it this way:

I have a focus but maybe unconsciously or subconsciously, we are learning words.

Another stated that,

In my view, I was learning vocabulary unconsciously. I think it is a language activity too, but I never thought of it that way before. I just search for material, for the article for information. 
One participant described the simultaneous process of searching for information and learning English in this way:

\section{Of course searching for information has something to do with the language. But... sometimes I look up the resources and there is one resource with a lot of unfamiliar words, I don't spend the time to find out, what does it mean ... But I do think it is a really good way to learn the language. And when I search something, there is a lot I have to read and comprehend.}

Most participants felt that using library strategies was an unconscious way to improve their English vocabulary but it was not the principal reason for them to engage in library database searching. Their principal focus, and therefore their conscious attention, was placed on finding appropriate sources of information.

Only four participants stated directly that using library strategies was equivalent to language learning. One participant who used this as a conscious way to learn English described it this way:

\section{The process of researching some words is like a language activity, helping myself to find the right word. And my best defi- nition is to find something. I can learn some words from this process. Different words, different meanings. And in the different contexts, different meanings. It is interesting for me.}

Another participant looked at it even more broadly and indicated that library database searching is just one of a myriad of ways in which people can engage in language learning:

You can learn new words doing anything.

Findings from this study seem to confirm the use of language strategies employed by international students when searching library databases. Both vocabu- lary strategies and library strategies were used to bolster and improve the English language vocabulary knowledge of the international students as they began to search for information.

\section{Discussion and Implications}

This study may add a piece to the library literature that examines how international students use university libraries. It directly ties library use to language learning from the perspective of international students. It does this by exploring general vocabulary learning strategies used during the search process. This study shifts the focus from failures that non-native speakers of English may experience when using English language library resources to more positive strategies they may be able to employ. Non-native proficiency in this study (library searching in English as a second language) assumes a greater importance than does foreign language proficiency (library searching in a native language other than English). Finally, this study acknowledges the importance of librarians assisting international students in their development of language learning strategies as a worthwhile way to help them become better information seekers in our libraries. Findings from this study highlight the importance of Reznowski's words, that "Librarians should be active in assisting language students with the identification of language learning opportunities."15

What might all this mean for both international students and librarians? It may mean that searching library databases could offer a potentially useful way for non-native speakers of English to learn language if they are made aware of it. In other words, if the students' attention could be turned to the language learning aspect of using library databases, they might gain doubly from engaging in this activity. They could learn to find information more effectively and they could broaden their own knowledge of English vocabulary. Their heightened skill level in English can then recursively be put 
to immediate use again in helping them conduct more successful searches. The binding of library database searching to simultaneous increased English language abilities could lead to future gains in both areas: improved searching efficiency and improved English proficiency.

How might librarians make international students more aware of the usefulness of developing their English vocabulary to improve their searching capabilities? One way might be to simply state directly to them that library database searching relies mainly on the computerized retrieval of word appearances. This statement of library fact can be done in person, through library instructions sessions, on a library Web site, or through faculty contacts. They should also be made aware that word frequency and word placement in a particular field (that is, in the subject heading field) often account for the reason searches result in particular hits. If international students understood this fundamental library database design principle, they might then give greater linguistic importance to the words they type into a database as an initial search. Another method might be asking international students inductively why they think they got certain search results from particular words or phrases. If they understood more clearly how library databases return and rank results, they may also see the value in selecting the most linguistically appropriate keywords from their own personal knowledge of English vocabulary.

A final reason that librarians might consider working with international students on vocabulary awareness issues with regard to database searching is that international students already have a large store of personal linguistic knowledge at their fingertips. Anyone who studies English as a non-native speaker generally has a built-in advantage over most native speakers in terms of conscious learning of English: their formal linguistic knowledge of the English language is already explicit. In other words, they are more consciously aware of regular and irregular patterns in English than native speakers because they cannot generally rely on the sense that something "just sounds right." Instead, non-native speakers usually have to look at a linguistic form in a more conscious way. They need to fit new language patterns into pre-existing patterns that have to be consciously learned. International students may therefore be prime candidates for learning how library databases explicitly function to consciously improve their own searching results. One comment from a participant in this study seems to emphasize this point. When describing what she does when a search is unsuccessful, she stated:

I try different words because that can help me find what I am looking for. Because it [the library database] is a computer, not a brain. So I can try "woman" instead of" female."

This particular participant understood quite clearly that most library databases are searching for the appearance of words in the explicit form in which they are entered. She therefore also knew that misspellings and typing mistakes could result in less useful results.

Library databases are generally not building invisible semantic bridges from one synonym to another by linking word meanings. The day may come when all library databases use sophisticated enough artificial intelligence algorithms to semantically reproduce what happens in our brains when we use language. That would be true natural language searching and not simply the stripping of stop words from search strings. At the present time, however, library database searching cannot replicate language processes in the human brain. Librarians therefore still have a role to play in helping students search effectively. We can help them consciously link the effective use of library databases to the effective use of linguistically appropriate English vocabulary. 


\section{Limitations}

The international students interviewed for this study were all graduate students in Applied Linguistics and Education. As such, their responses cannot be said to represent all graduate students in North America who are non-native speakers of English. Instead, their responses offer a glimpse of language learning strategies used in a library setting by students with a fairly high level of language learning knowledge brought to the task. A broader study with participants from a greater number of disciplines across more universities may be needed to verify findings from this study.

Another limitation may be my own personal bias in studying the relationships between language learning and library use. As a full-time practicing librarian, I also teach English as a Second Language (ESL) classes part-time and therefore have a foot in both worlds. My own inherent bias in working in both roles is to see a natural link between the two. I was also known to all the participants at the time of this study as their liaison librarian in the subject areas of both Education and Applied Linguistics. In addition, I was working as a language support specialist with the Education students on their writing at the time of this study. It is possible, therefore, that their personal knowledge of me in these roles may have influenced their responses to my questions. On the other hand, all participants brought a fairly sophisticated personal knowledge of language learning to this study and their responses were not coerced in any way by me. Having a known interviewer like myself conduct the interviews could therefore be seen as either a limitation or a strength.
A further limitation of the study is that all the actions identified by the participants were described secondhand to me. I did not directly observe their taking place. Future research studies may want to investigate these actions more directly and may also want to collect and assess levels of searching success. This study is only a starting point.

\section{Conclusion}

This study examined how graduate students who are non-native speakers of English decided what words to type into a library database when searching for information. Findings showed that most of these students relied on their own selfknowledge as a beginning point, followed by the use of vocabulary supplied to them by their instructors either individually or through lectures. When probed more deeply as to what strategies they used to find further words to enter into a database if their searches were initially unsuccessful, the participants identified and described a number of strategies. These strategies included both vocabulary and library strategies. The students generally felt that employing both types of strategies could be considered to be language learning, although many noted that using library strategies was not always a conscious method of learning more English words.

By shedding light on how international students who are non-native speakers of English use library databases, this study points to a connection between library database searching and language learning. In answer to the question "Is library database searching a language learning activity?" the initial answer appears to be yes.

\section{Notes}

1. Mary Beth Allen, "International Students in Academic Libraries: A User Survey," College E Research Libraries 54 (July 1993): 323-33; Yan Liao, Mary Finn, and Jun Lu, "Information-Seeking Behavior of International Graduate Students vs. American Graduate Students: A User Study at Virginia Tech 2005," College E Research Libraries 68 (Jan. 2007): 5-25.

2. Kaetrena D. Davis, Global Evolution: A Chronological Annotated Bibliography of International 
Students in U.S. Academic Libraries (Chicago: American Library Association, 2007).

3. Gina Macdonald and Elizabeth Sarkodie-Mensah, "ESL Students and American Libraries," College \& Research Libraries 49 (Sept. 1988): 428.

4. Miriam Conteh-Morgan, "Connecting the Dots: Limited English Proficiency, Second Language Learning Theories, and Information Literacy Instruction," Journal of Academic Librarianship 28 (July 2002): 191.

5. Li Wang, "Sociocultural Learning Theories and Information Literacy Teaching Activities in Higher Education," Reference \& User Services Quarterly 47 (2007): 149-58.

6. Dawn Amsberry, "Talking the Talk: Library Classroom Communication and International Students," Journal of Academic Librarianship 34 (June 2008): 354-57.

7. Tina Hurley, Nora Hegarty, and Jennifer Bolger, "Crossing a Bridge: The Challenges of Developing and Delivering a Pilot Information Literacy Course for International Students," New Library World 107 (2006): 302-20; Miriam E. Conteh-Morgan, "Empowering ESL Students: A New Model for Information Literacy Instruction," Research Strategies 18 (2001): 29-38; Lia Kamhi-Stein, "Teaching Information Competency as a Third Language: A New Model for Library Instruction," Reference E User Services Quarterly 38 (1998): 173-79; Dania M. Bilal, "International Students' Acquisition of Library Research Skills: Relationship with Their English Language Proficiency," Reference Librarian 24 (1989): 129-45.

8. Sara Baron and Alexia Strout-Dapaz, "Communicating with and Empowering International Students with a Library Skills Set," Reference Services Review 29 (2001): 314-26.

9. Pamela A. Jackson, "Incoming International Students and the Library: A Survey," Reference Services Review 33 (2005): 197-209.

10. Ann Curry and Deborah Copeman, "Reference Service to International Students: A Field Stimulation Research Study," Journal of Academic Librarianship 31 (Sept. 2005): 409-20.

11. Diane DiMartino, William J. Ferns, and Sharon Swacker, "CD-ROM Search Techniques of Novice End-Users: Is the English-as-as-a-Second-Language Student at a Disadvantage?" College $\mathcal{E}$ Research Libraries 56 (Jan. 1995): 56.

12. Fu Zhuo, Jenny Emanuel, and Shuqin Jiao, "International Students and Language Preferences in Library Database Use," Technical Services Quarterly 24 (2007): 1-13.

13. Karen Bordonaro, "Language Learning in the Library: An Exploratory Study of ESL Students," Journal of Academic Librarianship 32 (Aug. 2006): 518-26.

14. Alyousef Hesham Suleiman, "Teaching Reading Comprehension to ESL/EFL Learners," Reading Matrix: An International Online Journal 5 (Sept. 2005): 143-54.

15. Gabriella Reznowski, "The Librarian's Role in Motivating Language Learners: Tales from an Eastern Washington College Town," Reference Services Review 36 (2008): 422. 